\title{
Review of: "Neuromuscular blockade administration is associated with altered energy expenditure in critically ill intubated patients with COVID-19"
}

\author{
Patty Lakenman ${ }^{1}$, Koen Joosten ${ }^{1}$, Joanne Olieman ${ }^{1}$ \\ 1 Erasmus MC \\ Potential competing interests: The author(s) declared that no potential competing interests exist.
}

This is a comment on the recent work from Karayiannis et al. Their principal finding was that energy needs of intubated COVID-19 patients show a significant increase after the 1st week and have a tendency to stabilize after the 3rd week of ICU stay, whereby administration of neuromuscular blockade administration (NMBAs) may lower significantly resting energy expenditure (REE). Despite the small number $(n=34)$ of followed patients the study is valuable, however some considerations need to be addressed.

The researchers 'emphasize prevention of overfeeding among critically ill COVID-19 patients, especially during their first week of ICU stay'. Data on nutritional intake in this study was only determined within the first 48 hours after IC admission, subsequently they present that $71 \%$ of the enteral fed (EN) patients, $83 \%$ of parenteral fed (PN) and 79\% of the PN+EN combined fed received adequate nutritional intake. The method of determining nutritional requirements is not described, nor is it clear when this adequate intake was reached. The researchers described that feeding was started in $34 \%$ of the patients on day $1,41 \%$ at day 2 and $25 \%$ at day 3 . If we have read the methods correctly day 3 was not included in the collection of nutritional parameters. Thereafter, there is no data of administrated nutritional intake at the indirect calorimetry measurement days $\left(3^{\text {th }}, 7^{\text {th }}, 14^{\text {th }}, 21^{\text {th }}\right.$ and $28^{\text {th }}$ day) and it is unknown whether non-nutritional calories were taken into account. The study population was sedated with midazolam or propofol, the latter contains a proportional amount of calories (1). Assuming that adequate enteral feeding was provided continuously the thermic effect on REE may be negligible as opposed to bolus feeding, in which this effect could lead to an increase of approximately $10 \%$ for 3-6 hours $(2,3)$. In our study majority of COVID-19 patients were hypermetabolic receiving adequate continuously enteral feeding during the acute ( \pm day 4$)$ and late phase ( \pm day 10 ) of critical illness (4). In order to interpret the REE measurements correctly, feeding practices should be described. To assess hypermetabolism measured REE may be compared with predicted REE.

The results of the present study described a relative reduction of the metabolic rate in obese $(-12 \%)$ and non-obese (-22\%) COVID-19 patients receiving NMBA's compared with patients without NMBA's up to 3 
weeks of ICU admission. It is unknown whether influencing factors such as body temperature were taken into account for analysis. The researchers described that administration of NMBA's were more prevalent in the first week, but duration and dosage of NMBA's during the study are not described nor the number of obese versus non-obese patients over time. At baseline $35 \%(n=12)$ was obese and $76 \%$ of the patients received NMBA's which would imply that 3 obese patients didn't receive NMBA's versus 9 patients who did in the first 3 days, thereafter the numbers are unknown. These numbers seem too small to draw conclusions.

Other studies of the effect of NMBA's among critically ill sedated patients are contradictory. Sedation has been shown to significantly decrease $\operatorname{REE}(5,6)$, while administration of NMBA's in sedated patients may be of little influence on $\operatorname{REE}(7,8)$. REE is also influenced by several other factors such as metabolic disarrays and medical interventions (9). Data of longitudinal sedation doses and disease scores are unknown in the present study. At baseline most patients (68\%) were septic and it has been shown that septic patients seem to have a lower REE during the acute phase of disease compared with patients without sepsis $(10,11)$. So it is suggested to describe whether adjustments for disease scores were made for interpretation of REE measurements.

Limitations and weaknesses of the study were not addressed. The small number of patients seems to be a limitation to draw conclusions. Nevertheless, as the researchers stated critically ill COVID-19 are indeed likely to have increased energy needs after the first week of ICU admission $(4,12,13)$. Concerning clinical relevance determining individual energy needs of these patients should be based on frequently measured REE with indirect calorimetry. NMBA's should be included in the interpretation, as well as other factors that may be of influence for the phase of disease and therefore the measured $\operatorname{REE}(9,11)$.

\section{References}

1. Singer P, Blaser AR, Berger MM, Alhazzani W, Calder PC, Casaer MP, et al. ESPEN guideline on clinical nutrition in the intensive care unit. Clinical nutrition. 2019;38(1):48-79.

2. Heymsfield SB, Casper K, Funfar J. Physiologic response and clinical implications of nutrition support. The American journal of cardiology. 1987;60(12):G75-G81.

3. McClave SA, Snider HL. Invited review: use of indirect calorimetry in clinical nutrition. Nutrition in Clinical Practice. 1992;7(5):207-21.

4. Lakenman PLM, van der Hoven B, Schuijs JM, Eveleens RD, van Bommel J, Olieman JF, et al. Energy expenditure and feeding practices and tolerance during the acute and late phase of critically ill COVID-19 patients. Clinical Nutrition ESPEN. 2021.

5. Swinamer DL, Phang PT, Jones RL, Grace M, King EG. Effect of Routine Administration of Analgesia on Energy Expenditure in Critically III Patients. Chest. 1988;93(1):4-10.

6. Bruder N, Lassegue D, Pelissier D, Graziani N, François G. Energy expenditure and withdrawal of sedation in severe head-injured patients. Critical care medicine. 1994;22(7):1114-9. 
7. Freebairn RC, Derrick J, Gomersall CD, Young RJ, Joynt GM. Oxygen delivery, oxygen consumption, and gastric intramucosal pH are not improved by a computer-controlled, closed-loop, vecuronium infusion in severe sepsis and septic shock. Critical care medicine. 1997;25(1):72-7.

8. Bruder N, Raynal M, Pellissier D, Courtinat C, Francois G. Influence of body temperature, with or without sedation, on energy expenditure in severe head-injured patients. Critical care medicine. 1998;26(3):56872.

9. Rattanachaiwong S, Singer P. Indirect calorimetry as point of care testing. Clinical Nutrition. 2019;38(6):2531-44 .

10. Kreymann G, Grosser S, Buggisch P, Gottschall C, Matthaei S, Greten H. Oxygen consumption and resting metabolic rate in sepsis, sepsis syndrome, and septic shock. Critical care medicine. 1993;21(7):1012-9.

11. Wischmeyer PE. Nutrition therapy in sepsis. Critical care clinics. 2018;34(1):107-25.

12. Whittle J, Molinger J, MacLeod D, Haines K, Wischmeyer PE, Whittle J, et al. Persistent hypermetabolism and longitudinal energy expenditure in critically ill patients with COVID-19. Critical Care. 2020;24(1):581. 13. Yu PJ, Cassiere H, DeRosa S, Bocchieri K, Yar S, Hartman A. Hypermetabolism and COVID-19. JPEN Journal of Parenteral and Enteral Nutrition. 2020. 